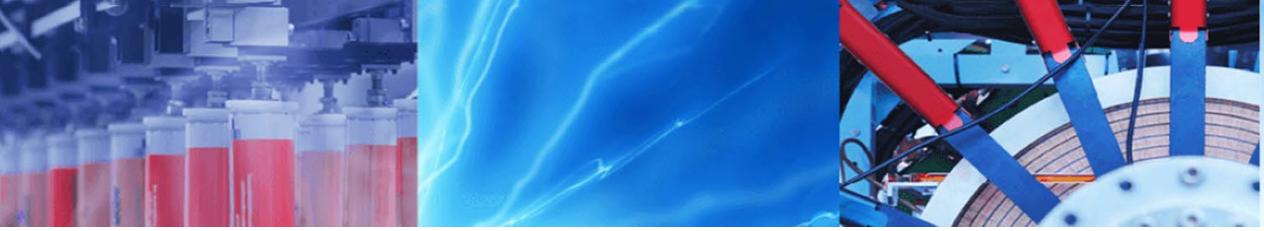

Research Article

\title{
The features of combustion of hydrogen and methane in oxygen and air in the presence of difluorodichloromethane additives
}

\author{
Nikolai M. Rubtsov ${ }^{1}$ (D) Alexey N. Vinogradov ${ }^{2}$ Alexander P. Kalinin ${ }^{3} \cdot$ Alexey I. Rodionov $^{4} \cdot$ Kirill Ya. Troshin $^{4}$. \\ Georgii I. Tsvetkov ${ }^{1} \cdot$ Boris S. Seplyarskii ${ }^{1}$
}

(c) Springer Nature Switzerland AG 2019

\begin{abstract}
It is shown that the inhibitor limit of ignition of the premixed methane-air mix makes 1 vol\% difluorodichloromethane at $1 \mathrm{~atm}$. It means that difluorodichloromethane is an effective inhibitor to prevent undesirable ignition of methane-air mixes at atmospheric pressure. It is experimentally shown that the concentration limits of the initiated combustion known from literature are meaningful only for previously prepared mixes. If the mixes are prepared just before the experiment, then the existence or the lack of ignition is determined by both an order of injection of mixture components, and the geometry of an installation. Therefore, the inhibition with halons can hardly be used to address the challenges of safety in mines. Thus, the influence of gasdynamic factors on the efficiency of inhibition is revealed. It is shown that the active centers of hydrogen and methane combustion determining the development of combustion process have the different chemical nature. Vibrationally excited molecules of hydrogen fluoride $(v=2,3)$ are for the first time detected in the products of combustion of hydrogen and methane in the presence of difluorodichloromethane by means of hyper spectrometers of visible and near infrared spectral range. It can be promising phenomenon in laser chemical applications. It is shown that in methane oxidation, the reaction with difluorodichloromethane leading to the formation of hydrogen fluoride $(v=2,3)$ has to include the active center of methane combustion.
\end{abstract}

Keywords Ignition · Combustion · Inhibition · Hydrogen · Methane · Air · Oxygen · Chemical mechanism · Halon · Hyperspectrometer $\cdot$ High speed filming

\section{Introduction}

The method of inhibition of flammable gas mixes is widely used in practice to provide fire and explosion safety of the equipment [1-3]. This problem is complicated by the Montreal Protocol on the restriction of the use of allegedly ozone-depleting substances, to which effective inhibitors of combustion-fluorochlorocarbons (named halons in applications of safety, or freons, if they are considered as coolants) were assigned.
Despite the ban, the ozone gap over Antarctica found in 1985 remains now almost as big as it was when the Montreal Protocol was signed in 1987. It is excessive to note that the global industrial factories and, especially, refrigeration units, are missing in Antarctica. However, the production of widely used chlorine-substituted halons such as promising combustion inhibitor and a coolant dufluorodichloromethane $\mathrm{CF}_{2} \mathrm{Cl}_{2}$ was stopped [4]. In particular, for consumers, it led to a significant increase in the cost of the equipment and prices for installation and service works [5].

$\triangle$ Nikolai M. Rubtsov, nmrubtss@mail.ru | ${ }^{1}$ Merzhanov Institute of Structural Macrokinetics and Material Science, Russian Academy of Sciences, Chernogolovka, Moscow Region, Russian Federation 142432. ${ }^{2}$ Joint Stock Company 'Reagent' Research and Development Center, Moscow, Russian Federation 125190. ${ }^{3}$ Ishlinsky Institute for Problems in Mechanics, Russian Academy of Sciences, Moscow, Russian Federation 119526. ${ }^{4}$ Semenov Institute of Chemical Physics, Russian Academy of Sciences, Moscow, Russian Federation 119991. 
Not only halons are promising fire inhibitors. It is known that some organophosphorus compounds [6] and organometallic compounds [4] inhibit combustion of hydrocarbons more efficiently than e.g. halon $\mathrm{CF}_{3} \mathrm{Br}$ by a factor of about 100 . However, they ignite in air and they are toxic, and therefore, they can be used only in places where human personnel are absent.

As compared with organophosphorus and organometallic compounds, chlorine-substituted halons do not ignite in the air under normal conditions, and they are safe for human personnel; these are only unbreathable. Among them difluorodichloromethane is the cheapest and safe one [7]. Unfortunately, due to the ban, the data on the inhibitor efficiency of $\mathrm{CF}_{2} \mathrm{Cl}_{2}$ are limited and contradictory.

The mechanism of flame inhibition by means of halons has not been fully understood. It is known that combustion and explosion are branched chain processes, in which the cycle of reactions (so-called a reaction chain) results in the reproduction of the active centers of the combustion [8]. If the additive, which reacts with the active centers, is injected into a zone of combustion then reaction chains are terminated; it leads to the inhibition of combustion. Notice that the specific reaction of branching (or the set of the reactions) in the course of methane combustion has not yet been established [9].

Thus, the termination with a molecule of inhibitor can be rather effective if the molecule reacts with the active center, which participates in a branching [10] or propagation [11] reaction step of a reaction chain. It is possible to find out the reaction only by means of kinetic or spectroscopic methods on the basis of direct measurement of the reaction rate of this active center with an inhibitor.

Another experimental possibility of establishment of the chemical nature of the elementary steps, which are responsible for branching and termination of reaction chains, is the analysis of the limit phenomena in inhibition of gas flames, as these phenomena are caused by the competition of branching and termination of active centers via reaction with the inhibitor. It is shown in [12] that the most effective "ozone-safe" inhibitor is $\mathrm{C}_{4} \mathrm{~F}_{10}$; its minimum effective concentration makes 6 vol\%. However, the concentration of methane in the stoichiometric mix makes about 9 vol\%, i.e. the concentration of fuel is comparable with that of inhibitor. In that case the additive may cause the change in fuel composition and withdraw the mixture out of the ignition area. Thus, the term "inhibitor" is inapplicable and it is necessary to use the terms "diluent", "retardant" or "suppressant".

It should be noted that the vast majority of the accidents involving methane explosion take place at atmospheric pressure. Hence, it is important to have an effective (less than 10 vol\% to fuel) and a safe inhibitor to reduce the risk of accidents. However, as can be seen from above, the effective amount of the perfluorinated halon additive is $\geq 6$ vol\% being comparable with fuel concentration.

The establishment of the mechanism of halon inhibition in the case of the reaction of hydrogen oxidation or $\mathrm{CO}$ oxidation in the presence of hydrogen is a relatively clear problem because a reaction of chain branching in these processes is known: $\mathrm{H} .+\mathrm{O}_{2} \rightarrow \mathrm{O} . .+\mathrm{OH}$. (the comma indicates a free valence) [8]. Atoms $\mathrm{H}$ participate in this reaction; therefore, the reactions of $\mathrm{H}$ atoms with halon or the products of its decomposition can be the competing reactions of chain termination, because reactions $\mathrm{O}$. or $\mathrm{OH}$. with halon do not lead to chain termination; when only $\mathrm{OH}$. is terminated, the branching is even maintained.

In addition, there is no reason to consider that atoms $\mathrm{H}$ play the leading role in methane oxidation. Really, in the works $[13,14]$ it is assumed that the role of $\mathrm{H}$ atoms in hydrocarbon oxidation is not determining one and consists, at least, in participation in longer chains, than at hydrogen oxidation.

Notice that the estimate of a rate constant at room temperature of termination via $\mathrm{CF}_{2} \mathrm{Cl}_{2}$ is given in [15]: $\mathrm{k}(\mathrm{H}+$ $\left.\mathrm{CF}_{2} \mathrm{Cl}_{2}\right)=5 \times 10^{12} \exp (-9500 / \mathrm{RT}) \mathrm{cm}^{3} \mathrm{~mol}^{-1} \mathrm{~s}^{-1}$. It means that hydrogen atoms react with halon molecules in the primary center of ignition at $1000 \mathrm{~K}$ (experimental value of gas temperature in a spark ignition zone [14]); it can provide inhibition [14].

The work is aimed at the establishment of the inhibition efficiency of $\mathrm{CF}_{2} \mathrm{Cl}_{2}$ additives in the reactions of hydrogen and methane combustion in air and oxygen as well as identification of influence of gas dynamic factors on the efficiency of inhibition. The latter is important in practical applications: e.g. in mines, the premixed methane-inhibitor mix cannot be created anyway, because methane can leak out of the place, unknown in advance. A traditional optical emission spectroscopy and hyper spectrometers of visible and near infrared spectral range were used for the establishment of the nature of the light emitting particles in the presence of halon additive in order to obtain new data on the chemical mechanism of the action of the additive.

\section{Experimental}

In experiments, two installations were used. In the first installation (installation 1), both hyper spectrometers and a high-speed color digital camera were used for registration of light emission. The analysis of optical and NIR spectra of combustion of hydrogen and methane in oxygen and air at atmospheric and reduced pressures was carried out. Hyper spectrometers allowed to perform 4D measurements, namely, the 1 st dimension is time, 2 nd one-wavelength, 3rd one-spectral intensity at this 
wavelength, 4th one-coordinate of the fragment of an emitting source. In the second installation (installation 2), the spectrograph with crossed dispersion equipped with a digital video camera was used for emission recording. The spectrograph had higher resolution than an optical hyper spectrometer; it allowed to carry out the exact assignment of spectra.

The stainless steel reactor $25 \mathrm{~cm}$ long and $12 \mathrm{~cm}$ in diameter was supplied with a tangential gas input (noted by a blue circle in Fig. 1a, b), removable covers and an optical quartz window. Experiments were performed at initial room temperature. The pumped-out reactor was filled with a gas mix from the high pressure buffer volume up to the necessary pressure; flame initiation was carried out with a spark discharge (1.5 J). If a gas mixture was prepared immediately in the reactor, the components of the mix were injected via the open valve of the tangential input. Because of a sharp pressure difference in the buffer volume and the reactor, a gas whirl occurs in the reactor leading to the reduction of mixing time $[16,17]$.

The pressure in the process was recorded by means of the tensoresistive Carat DI sensor, from which the signal was transmitted to the computer via A/D converter. The value of the extent of expansion of combustion products $\varepsilon_{\mathrm{T}}$ was determined by the value of the maximum pressure $\mathrm{P}_{\mathrm{b}}$ developed in the course of combustion of the $\operatorname{mix}[1,3]: P_{b} / P_{0}=1+\gamma\left(\varepsilon_{T}-1\right)$, the value of normal velocity of flame propagation $U_{n}$ was determined from a ratio $[1,3]: U_{n}=V_{v} / \varepsilon_{T} . P_{0}$ is initial pressure, $\gamma$ is an isentropic exponent of an initial mix, $\mathrm{V}_{\mathrm{v}}$-a visible flame velocity. Before each experiment the reactor was pumped out to
$10^{-1}$ Torr. Pressure in the reactor was controlled with a standard vacuum gage, and in the buffer volume - with a standard pressure gage. Gases $\left(\mathrm{H}_{2}, \mathrm{O}_{2}, \mathrm{CH}_{4}, \mathrm{CF}_{2} \mathrm{Cl}_{2}\right)$ were of chemically pure grade.

Fuel mixtures were mainly stoichiometric ones (see below), and the inhibitor was added in an amount of $X$ vol\%. The inhibitor concentration limit was considered as a mean inhibitor concentration $X$ vol\%, further $X \%$; at $(X+0.1 X) \%$ the initiated ignition occurs, at $(X-0.1 X) \%$ it does not occur, all other things being equal. The pumpdown time between experiments was $2 \mathrm{~h}$.

Recording of the light emission during combustion was carried out by means of the spectrograph with crossed dispersion STE-1 supplied with the color Sony DCR_SR200E video camera (installation 2); or a hyper spectrometer and a color high-speed movie camera Casio Exilim F1 Pro through an optical window in a removable cover (Fig. 1). Hyper spectrometers sensitive over $400-970 \mathrm{~nm}$ range and over the near infrared range 970-1700 nm [18] were used. The experiments on high-speed filming were performed with gas mixes $\left(\mathrm{H}_{2}+\text { air }\right)_{\text {stoich }}+10 \%$ $\mathrm{CF}_{2} \mathrm{Cl}_{2},\left(\mathrm{CH}_{4}+\text { air }\right)_{\text {stoich }}+0 \div 10 \% \mathrm{CF}_{2} \mathrm{Cl}_{2},\left(\mathrm{H}_{2}+\mathrm{O}_{2}\right)_{\text {stoich }}$ $+10 \% \div 15 \% \mathrm{CF}_{2} \mathrm{Cl}_{2},\left(\mathrm{CH}_{4}+\mathrm{O}_{2}\right)_{\text {stoich }}+10 \% \div 15 \% \mathrm{CF}_{2} \mathrm{Cl}_{2}$, $7 \% \mathrm{CH}_{4}+$ air $+0 \div 1 \% \mathrm{CF}_{2} \mathrm{Cl}_{2}, 11 \% \mathrm{CH}_{4}+$ air $+0 \div 1 \% \mathrm{CF}_{2} \mathrm{Cl}_{2}$. The obtained data were processed and stored in computer memory for the further analysis.

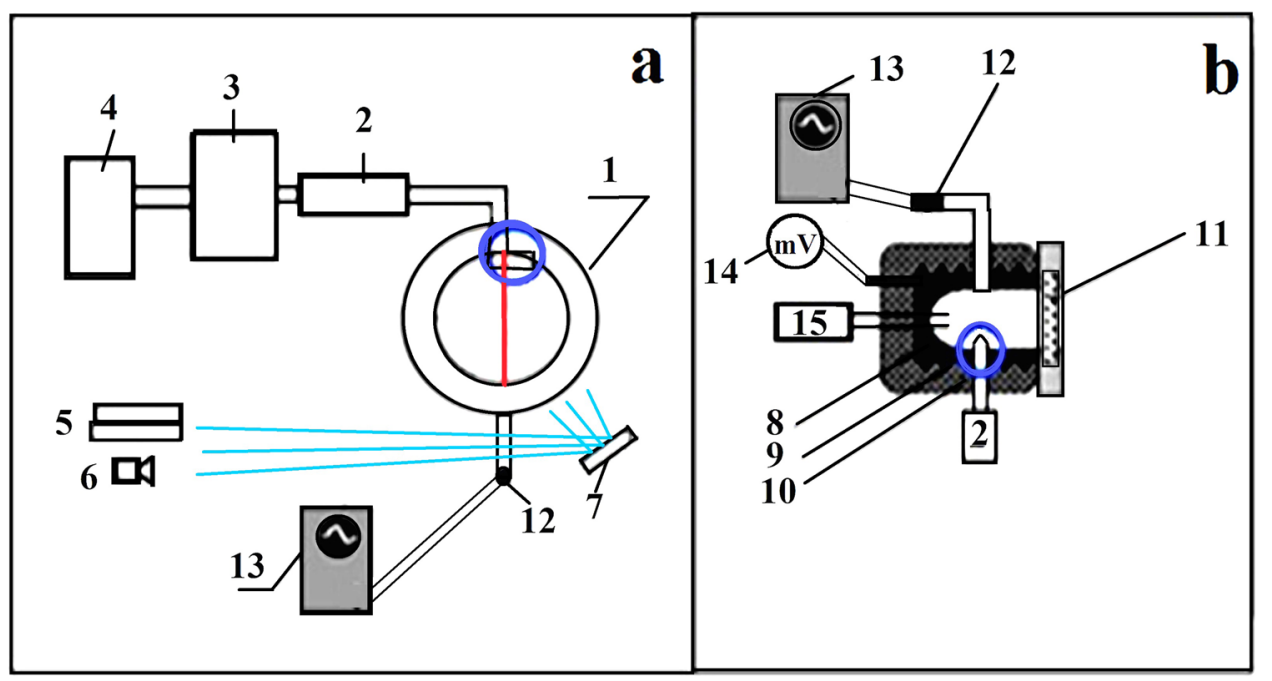

Fig. 1 Installation 1. a Scheme of experimental installation; b scheme of the reactor. The warmed-up reactor 1 , electromagnetic valve 2 , buffer volume 3 , cylinder with a gas mix 4 , hyper spectrometers 5 , digital video camera 6 , rotary mirror 7 , internal asbestos isolation 8 , heater 9 , external asbestos isolation 10 , optical window 11 , pressure sensor $12, \mathrm{~A} / \mathrm{D}$ converter and computer for data storage and analysis 13 , millivolt meter and thermocouple 14, spark ignition 15. The red line, on which 4D-spectral shooting is carried out is shown in a. The width of this line is about $1 \mathrm{~mm}$. The blue circle notes the tangential input of gas into the reactor 


\section{Results and discussion}

It was shown that $10 \% \mathrm{CF}_{2} \mathrm{Cl}_{2}$ additive does not have a noticeable inhibiting effect on the combustion of the previously prepared mix $\mathrm{H}_{2}$-air in consent with [19]. If an estimate of the rate constant of the reaction $\mathrm{H}+\mathrm{CF}_{2} \mathrm{Cl}_{2} 5 \times 10^{12} \exp (-9500 / \mathrm{RT}) \mathrm{cm}^{3} \mathrm{~mol}^{-1} \mathrm{~s}^{-1}[15]$ is true one, $\mathrm{H}$ atoms are terminated via halon molecules in the primary center of ignition at $1000 \mathrm{~K}$ (experimental value of gas temperature in a spark ignition zone [14, p. 93]). The observed weak inhibition means that $\mathrm{CF}_{2} \mathrm{Cl}_{2}$ molecules participate also in some competing reactions of the development of reaction chains.

However, just $2 \% \mathrm{CF}_{2} \mathrm{Cl}_{2}$ additive in the previously prepared stoichiometric mix of methane with air completely inhibits the initiated ignition. The experiments on the preparation of a gas mix immediately in the reactor were performed. It was shown that the gas mixture prepared by the first injection of $2 \% \mathrm{CF}_{2} \mathrm{Cl}_{2}$ and then stoichiometric mix $\mathrm{CH}_{4}+$ air up to 1 atm, cannot be ignited. However, if the mix is prepared in reverse order (first stoichiometric mix $\mathrm{CH}_{4}$ + air is injected, and then $\mathrm{CF}_{2} \mathrm{Cl}_{2}$ to $\left.1 \mathrm{~atm}\right)$, then ignition occurs already at $4 \% \mathrm{CF}_{2} \mathrm{Cl}_{2}$ (Fig. 2a, b).

Notice that in the presence of halon the pressure jump is higher, than in its absence (Fig. 2 right at the top). As this pressure jump is caused by heat release in the combustion [20], it means that at methane oxidation in the presence of halon, additional heat is released, i.e. halon does not act as a diluent, it participates in the combustion.

Thus, the concentration limits of the initiated combustion known from the literature are meaningful only for previously prepared mixes. If the mixes are prepared just before the experiment, then the existence or the lack of ignition is determined by both an order of injection of
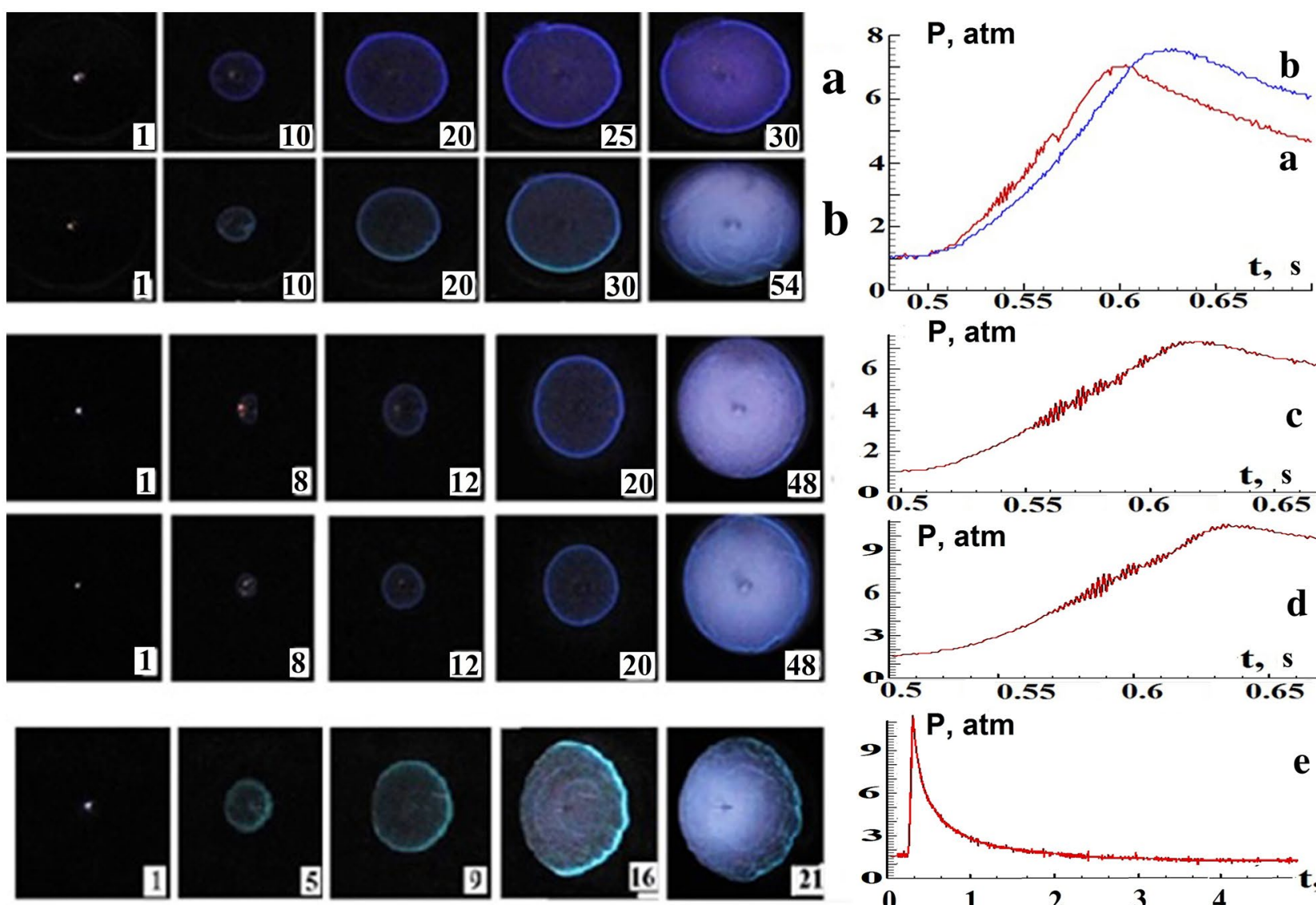

48
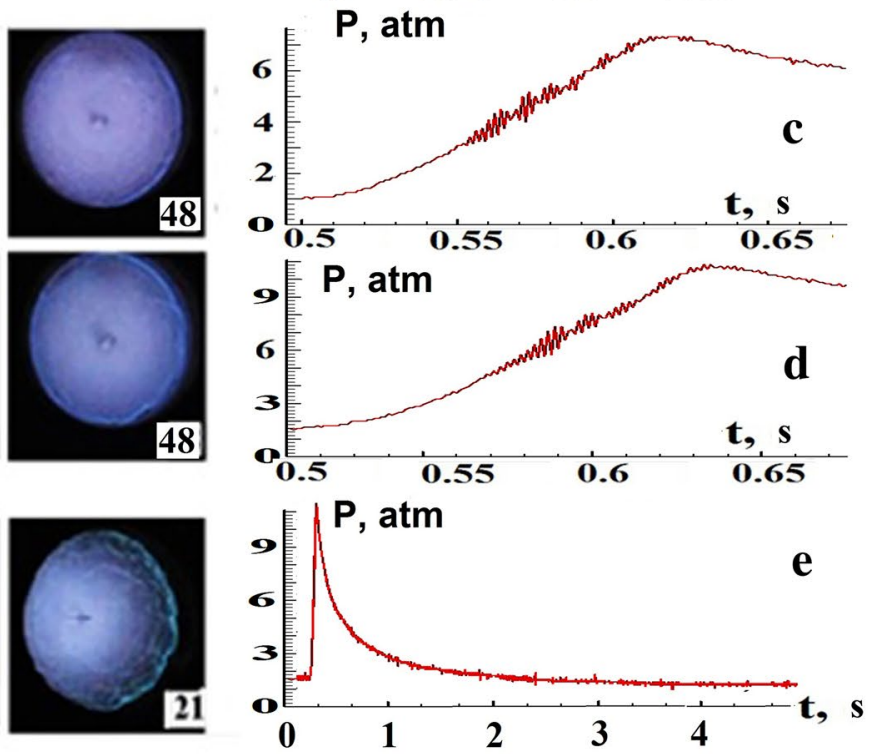

Fig. 2 High-speed filming of the flame front propagation initiated

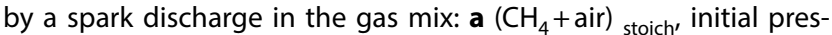
sure is $1 \mathrm{~atm}, \mathbf{b}\left(\mathrm{CH}_{4}+\right.$ air) ${ }_{\text {stoich }}+4 \% \mathrm{CF}_{2} \mathrm{Cl}_{2}$. First methane mix with air is injected, then $4 \% \mathrm{CF}_{2} \mathrm{Cl}_{2}$ to $1 \mathrm{~atm}$. The mix, prepared in reverse order, does not burn. Oscillograms of pressure changes at the initiated ignition of mixes $\mathbf{a}$ and $\mathbf{b}$ are shown on the left. $\mathbf{c}$ ignition of previously prepared mix $\left(\mathrm{CH}_{4}+\right.$ air) ${ }_{\text {stoich }}+1 \% \mathrm{CF}_{2} \mathrm{Cl}_{2}$, initial pressure $1 \mathrm{~atm}$. $\mathbf{d}$ ignition of the same mix at initial pressure $1.5 \mathrm{~atm}$. Oscil- lograms of pressure change at the initiated ignition are shown on the right. e premixed mixture $40 \% \mathrm{H}_{2}+$ air in the presence of $10 \%$ $\mathrm{CF}_{2} \mathrm{Cl}_{2}$. Initial pressure $1.5 \mathrm{~atm}$. The video camera is located on the side of the reactor; in front of the reactor there hyperspectrometers are placed. Pressure change dependency on time during ignition is shown on the right. The figure on a shot corresponds to a number of a shot after initiation, 600 frames/s

\section{SN Applied Sciences}




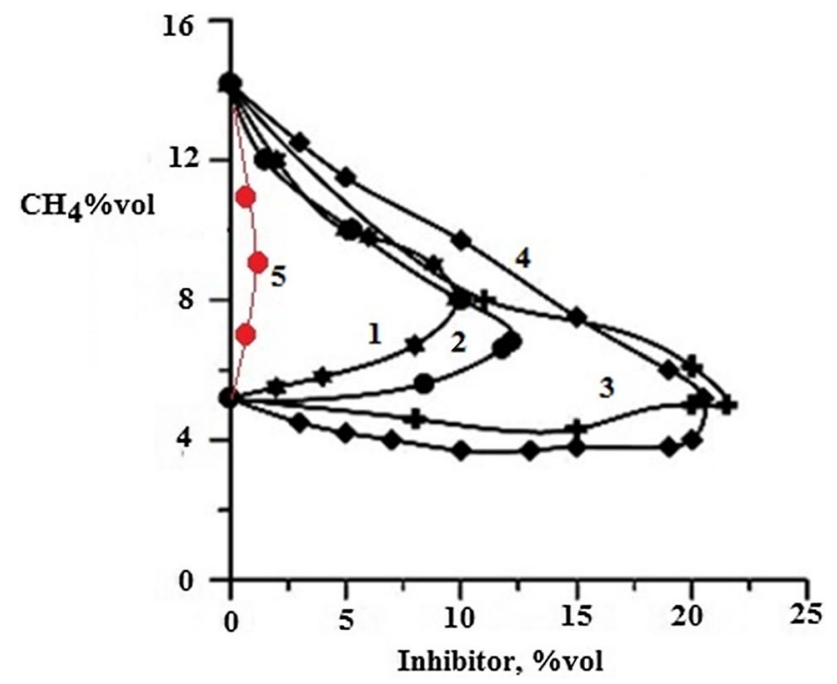

Fig. 3 Influence of various inhibitors on the flammability limits of methane in air: $1-\mathrm{C}_{2} \mathrm{~F}_{4} \mathrm{Br}_{2}, 2-\mathrm{C}_{2} \mathrm{~F}_{5} \mathrm{H}$, 3-NAFS-III (mixture of fluorinated hydrocarbons), $4-\mathrm{CHF}_{3}, 5-\mathrm{CH}_{2} \mathrm{~F}_{2}$. 1-4 experimental data from [19], 5-this work

mixture components, and the geometry of an installation. Therefore, the inhibition with halons can hardly be used to solve the problems of safety in mines: there a premixed methane-inhibitor mix cannot be created anyway, because methane can leak out of the place, unknown in advance. It was shown that in the reactor, which is not treated by ignitions, it is possible to initiate the ignition of a previously prepared mix $\left(\mathrm{CH}_{4}+\right.$ air) ${ }_{\text {stoich }}+1 \% \mathrm{CF}_{2} \mathrm{Cl}_{2}$ (Fig. $2 \mathrm{c}$ ); it is possible to ignite this mix at $1.5 \mathrm{~atm}$ only after $30 \mathrm{~min}$ pumping (Fig. $2 \mathrm{~d}$ ). Thus, even small amounts of reaction products, e.g. of water vapor, make considerable impact on the value of the limit of the initiated ignition. The visible flame velocity at the limit is lower than that of the mix without inhibitor; the flame front in the presence of inhibitor has cellular shape. As is seen in Fig. 2 (down on the right), the flame propagation is followed by flame pressure oscillations, i.e. has unstable character.

Pressure oscillations and the cellular flame shape indicate the proximity of the mix containing $1 \% \mathrm{CF}_{2} \mathrm{Cl}_{2}$ to the limit of the initiated ignition $[1,20]$. In this case $\mathrm{CF}_{2} \mathrm{Cl}_{2}$ is not a retardant, but an effective inhibitor, which operating concentration is almost 10 times less than fuel concentration. Indeed, in that case the additive cannot cause the change in fuel composition and withdraw the mixture out of the ignition area. The results of the experiment on ignition of leaner and richer non-stoichiometric mixtures showed that inhibitor limits make $0.5 \%$ for $7 \%$ methane -air and $0.5 \%$ for $11 \%$ methane-air mixes; these values in comparison with the data [20] indicate the high effectiveness of $\mathrm{CF}_{2} \mathrm{Cl}_{2}$ additives (Fig. 3).
Thus, under conditions of the same installation, the inhibitor limit of the mix $\left(\mathrm{H}_{2}+\text { air }\right)_{\text {stoich }}$ in the presence of $\mathrm{CF}_{2} \mathrm{Cl}_{2}$ exceeds $10 \%$; at the same time the inhibitor limit of the mix $\left(\mathrm{CH}_{4}+\text { air }\right)_{\text {stoich }}$ makes $1 \% \mathrm{CF}_{2} \mathrm{Cl}_{2}$. It means in consent with $[12,21]$, that in the work, the evidence is obtained that the active centers of methane and hydrogen combustion, which determine flame propagation, have different chemical nature.

In Fig. 4, visible and near IR emission spectra of combustion of the mix $\left(\mathrm{H}_{2}+\text { air }\right)_{\text {stoich }}$ in the presence of $10 \% \mathrm{CF}_{2} \mathrm{Cl}_{2}$ are shown. It is seen in Fig. 4a that the most intensive visible bands are observed over the range $850-1000 \mathrm{~nm}$; these can be assigned to HF $(v=3)$ [22]. Notice that as the flame propagates with a visible velocity $210 \mathrm{~cm} / \mathrm{s}$, and $\varepsilon=12.5$ from Fig. 2e, the normal flame velocity is $16.8 \mathrm{~cm} / \mathrm{s}$ (see experimental). It is about 15 times less than the normal velocity of flame propagation without halon additive [3]. Thus, the warming up in the flame front is comparably small; therefore, the bands of alkali metals ( $\mathrm{Na}$ and $\mathrm{K}$ ) characteristic of hot flames have low intensity in the spectrum.

In Fig. 4b, near IR emission spectrum of combustion of the mix $\left(\mathrm{H}_{2}+\text { air }\right)_{\text {stoich }}$ in the presence of $10 \% \mathrm{CF}_{2} \mathrm{Cl}_{2}$ is shown. We carried out the line assignment, using the data [23] presented in Fig. 4c. It follows from the comparison of Fig. $4 \mathrm{~b}, \mathrm{c}$ that the bands at $1.25 \mu \mathrm{m}$ and $1.32 \mu \mathrm{m}$ relate to vibrationally excited molecules $\mathrm{HF}(\mathrm{v}=2)$. The wide band at $1.4 \mu \mathrm{m}$ is caused by $\mathrm{H}_{2} \mathrm{O}$ radiation [23]. This assignment is illustrated in Fig. 4 d, in which a near IR emission spectrum of the mix $\left(\mathrm{H}_{2}+\right.$ air) stoich in the presence of $10 \% \mathrm{CF}_{2} \mathrm{Cl}_{2}$ (red curve), imposed on a near IR emission spectrum of the mix $\left(\mathrm{H}_{2}+\text { air }\right)_{\text {stoich }}$ is presented. As is seen, Fig. $4 \mathrm{~d}$ adequately approximates the spectrum shown in Fig. $4 \mathrm{~b}$.

Thus, in combustion products of the mix $\left(\mathrm{H}_{2}+\text { air }\right)_{\text {stoich }}$ in the presence of $10 \% \mathrm{CF}_{2} \mathrm{Cl}_{2}$, the molecules $\mathrm{HF}(\mathrm{v}=2)$ and $(v=3)$ are detected. Notice that molecules HF in the zero vibrational state were observed in [24] in this reaction. It should be noted that IR data [24] of the products of $\mathrm{H}_{2}+\mathrm{O}_{2}+\mathrm{CF}_{2} \mathrm{Cl}_{2}$ combustion allow identifying $\mathrm{HF}(\mathrm{v}=0)$, $\mathrm{CF}_{4}, \mathrm{COF}_{2}$ and $\mathrm{CF}_{3} \mathrm{Cl}$. $\mathrm{HCl}$ was not detected. FTIR data [25] of the products of $\mathrm{CH}_{4}+\mathrm{O}_{2}+\mathrm{CF}_{3} \mathrm{Br}$ allow identifying $\mathrm{HF}$ $(\mathrm{v}=0), \mathrm{CF}_{4}, \mathrm{COF}_{2}, \mathrm{H}_{2} \mathrm{O}$ and $\mathrm{CO}_{2}$. $\mathrm{HBr}$ bands are very weak, i.e. the amount of halogen hydrides (except HF) in the products is probably small; it must be taken into account in considering the mechanism of inhibition with halons.

We also detected molecules HF $(v=3)$ at inhibition of natural gas combustion with octadecafluorodecahydronaphthalene ("artificial blood", perfluorodecaline $\mathrm{C}_{10} \mathrm{~F}_{18}$ ) [26]. The reaction, in which enough energy can be emitted $\left(11,100 \mathrm{~cm}^{-1}=1.38 \mathrm{eV}=37 \mathrm{kcal} / \mathrm{mole}\right)$ to provide vibrational excitation of HF molecules $(v=3)$, is almost a thermally neutral reaction $[14,26,27]$ :

$\mathrm{H}+\mathrm{CF}_{2} \mathrm{Cl}_{2} \rightarrow \mathrm{HF}+\mathrm{CFCl}_{2}$ 

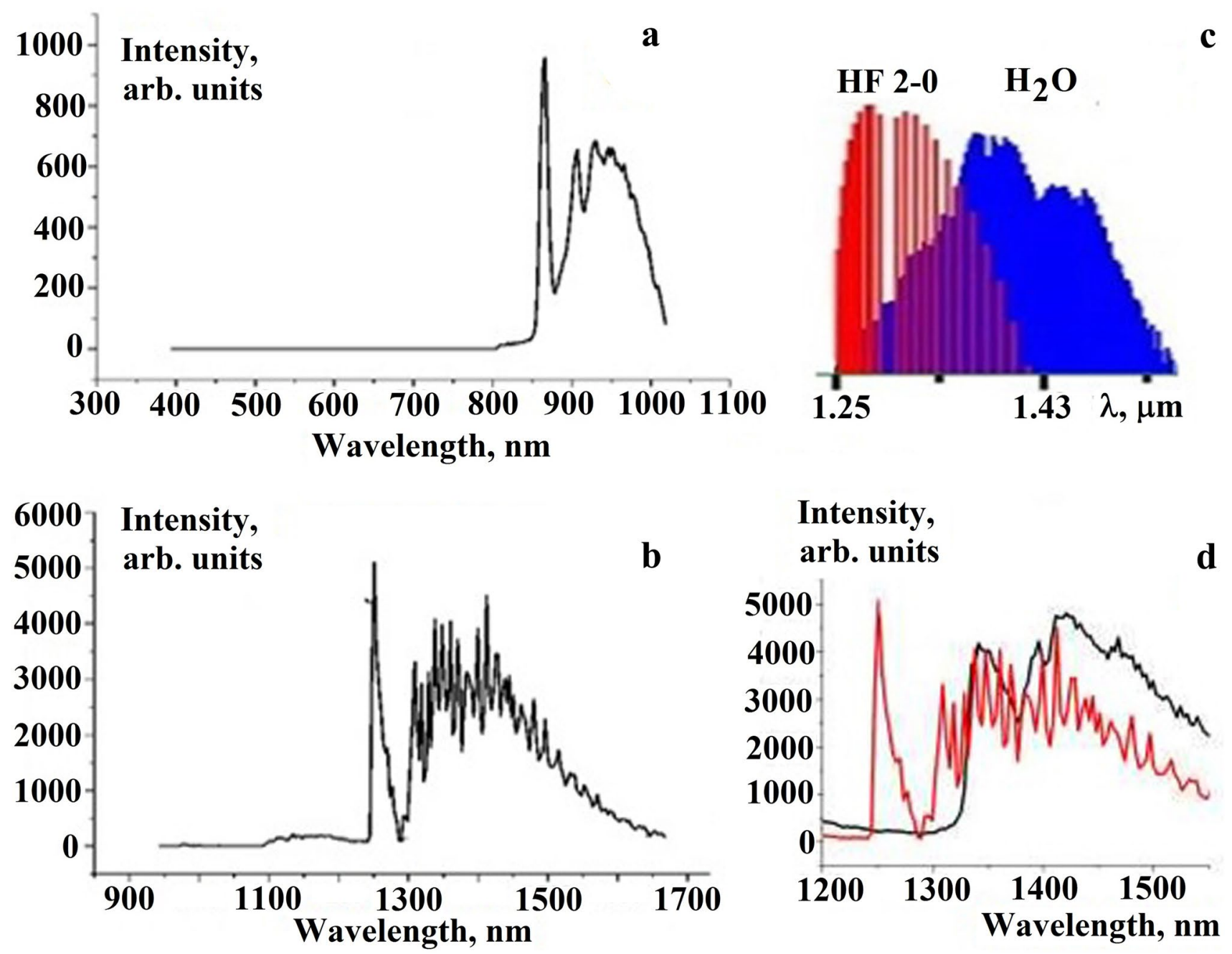

Fig. 4 Emission spectra of combustion of the mix $\left(\mathrm{H}_{2}+\text { air }\right)_{\text {stoich }}$ in the presence of $10 \% \mathrm{CF}_{2} \mathrm{Cl}_{2}$ at $1.5 \mathrm{~atm}$ in visible (a) and near IR area (b), recorded with hyper spectrometers, $\mathbf{c}$ near IR emitting bands of $\mathrm{HF}(\mathrm{v}=2)$ and $\mathrm{H}_{2} \mathrm{O}$ according to [23], $\mathbf{d}$ a near IR emission spec-

trum of the mix $\left(\mathrm{H}_{2}+\text { air }\right)_{\text {stoich }}$ in the presence of $10 \% \mathrm{CF}_{2} \mathrm{Cl}_{2}$ (red), imposed on a near IR emission spectrum of the mix $\left(\mathrm{H}_{2}+\text { air }\right)_{\text {stoich }}$

Since the inhibitor concentration limit of the stoichiometric methane-air mixture is about $1 \% \mathrm{CF}_{2} \mathrm{Cl}_{2}$, the intensity of $\mathrm{HF}$ emission is indeed rather low to compare with $\mathrm{HF}$ intensity at hydrogen combustion in the presence of the same amount of halon.To increase the sensitivity of the technique by means of addition of greater amounts of halon, oxygen mixes instead of air mixes were used.

We draw the attention of the reader to the fact, that the measurement of the inhibitor concentration limit is especially relevant for fuel-air combustion at atmospheric pressure, that is, for conditions where the issue of explosion safety arises. In the experiments, when oxygen was used instead of air, the formation of excited particles in the combustion processes studied was investigated; explosion safety issues and, accordingly, inhibitor concentration limits upon combustion in oxygen under reduced pressure were not considered.

In addition, we showed that the inhibitor limit of the mix $\left(\mathrm{CH}_{4}+\text { air }\right)_{\text {stoich }}$ makes $1 \% \mathrm{CF}_{2} \mathrm{Cl}_{2}$, while, as is shown below, the mix $\left(\mathrm{CH}_{4}+\mathrm{O}_{2}\right)_{\text {stoich }}+15 \% \mathrm{CF}_{2} \mathrm{Cl}_{2}$ can be ignited at 100 Torr. It provides a rough estimate of the inhibitor concentration limits of methane-oxygen mixtures, which are significantly greater than those of methane-air mixtures (Rev\#1).

In the experiments described below, gas mixes $2 \mathrm{H}_{2}+\mathrm{O}_{2}+10 \% \div 15 \% \mathrm{CF}_{2} \mathrm{Cl}_{2}$ and $\left(\mathrm{CH}_{4}+\mathrm{O}_{2}\right)_{\text {stoich }}+10 \% \div 15 \%$ $\mathrm{CF}_{2} \mathrm{Cl}_{2}$ were used. In Fig. 5, the results of experiments in installation 2 are presented; the assignment of spectral bands of HF $(v=3)$ on the basis of a spectrum with higher resolution is carried out. 

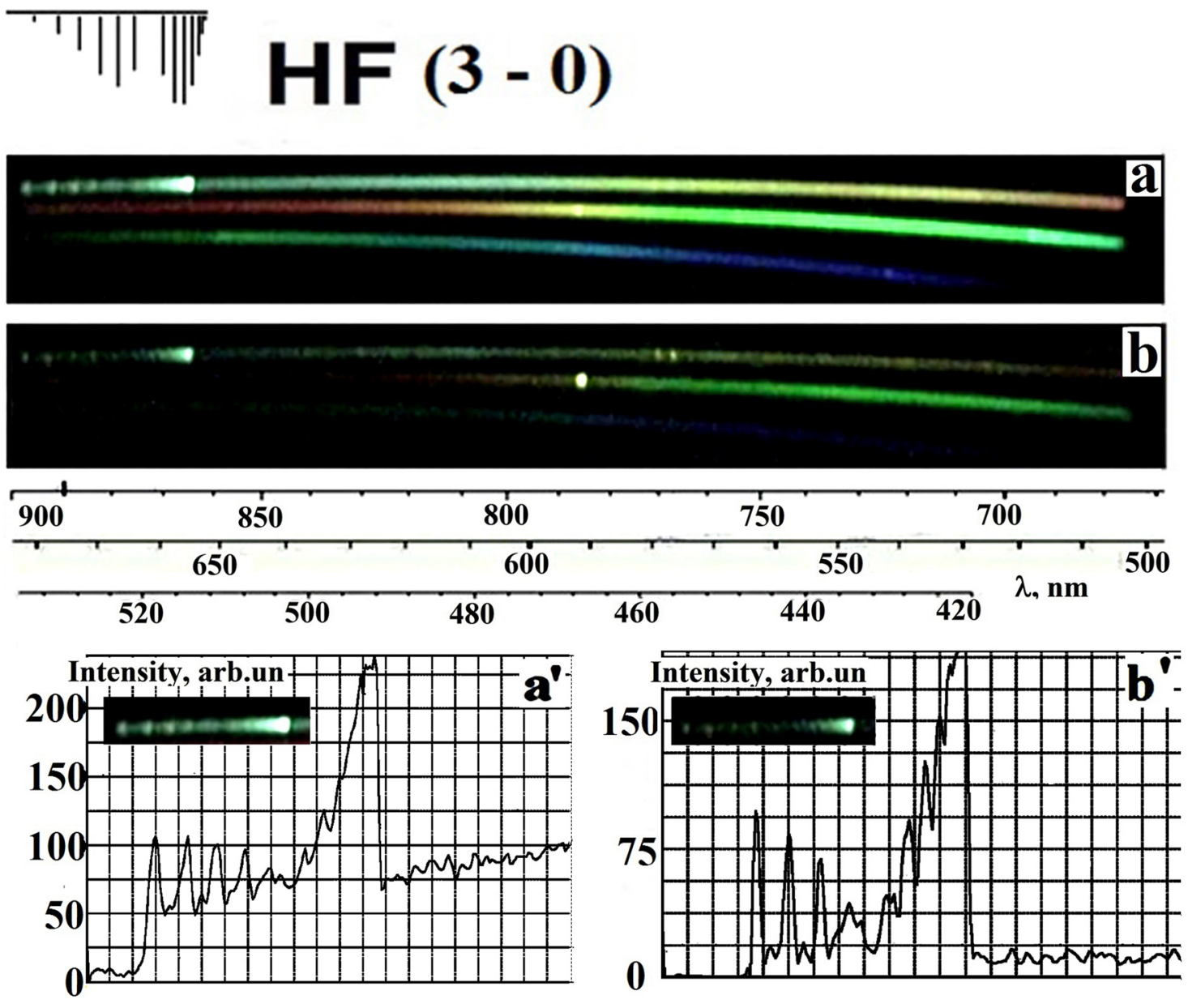

Fig. 5 Emission flame spectra at initial pressure 100 Torr: a $\left(\mathrm{CH}_{4}+\mathrm{O}_{2}\right)_{\text {stoich }}+10 \% \mathrm{CF}_{2} \mathrm{Cl}_{2}$, b $\left(\mathrm{H}_{2}+\mathrm{O}_{2}\right)_{\text {stoich }}+10 \% \mathrm{CF}_{2} \mathrm{Cl}_{2}$, a' the region of the spectrum a, corresponding to the emission of $\mathrm{HF}$ $(v=3) 0.87-0.91 \mu \mathrm{m}$ processed by means of the Hesperus 3.0 program $\mathbf{b}^{\prime}$ the region of the spectrum $\mathbf{b}$, corresponding to the emis-

In the following series of experiments, the dependence of the change of a signal intensity of HF $(v=2)$ and $(v=3)$ on concentration of $\mathrm{CF}_{2} \mathrm{Cl}_{2}$ was investigated. In Fig. 6 , the emission spectra of the mixes $2 \mathrm{H}_{2}+\mathrm{O}_{2}+10 \%$ and $15 \% \mathrm{CF}_{2} \mathrm{Cl}_{2}$ and $\left(\mathrm{CH}_{4}+\mathrm{O}_{2}\right)_{\text {stoich }}+10 \%$ and $15 \% \mathrm{CF}_{2} \mathrm{Cl}_{2}$ recorded over intervals 400-970 $\mathrm{nm}$ (Fig. 6a, b) and 970-1700 $\mathrm{nm}$ at an initial pressure of 100 Torr are shown (Fig. 6c, d). The spectrum with maximum intensity was chosen from the time sequence of the spectra for each experiment.

As is seen from Fig. 6 , the emission of $\mathrm{HF}(v=2,3)$ is also observed in the combustion of the stoichiometric methane-oxygen mix in the presence of $10 \% \mathrm{CF}_{2} \mathrm{Cl}_{2}$; in addition, the maximum intensity of $\mathrm{HF}$ bands $(v=2,3)$ in methane combustion is higher, than in $2 \mathrm{H}_{2}+\mathrm{O}_{2}$ combustion in the presence of the same amount of halon.

sion of HF $(v=3) 0.87-0.91 \mu \mathrm{m}$ processed by means of the Hesperus 3.0 program. The emission spectrum of HF $(v=3)[31]$ is shown on top. Three lines on each spectrum from top to bottom belong to spectral intervals $910-670 \mathrm{~nm}, 680-500 \mathrm{~nm}, 550-420 \mathrm{~nm}$ respectively

It appears unlikely that the maximum concentration of $\mathrm{H}$ atoms in $\mathrm{CH}_{4}$ combustion is larger than in $\mathrm{H}_{2}$ combustion. In addition, the active centers of the combustion of hydrogen and methane determining the development of the combustion process differ from each other. It means that the reaction with $\mathrm{CF}_{2} \mathrm{Cl}_{2}$ leading to formation of $\mathrm{HF}$ $(v=2,3)$ in methane combustion includes the active center of methane combustion rather than hydrogen combustion. As $\mathrm{CF}_{2} \mathrm{Cl}_{2}$ is an effective inhibitor of methane combustion, this active center has to participate in the elementary act of branching or propagation of a reaction chain as well as to contain a hydrogen atom to form HF molecule.

The data on rate constants of elementary reactions, which are accessible in the literature are limited and contradictory, i.e. the available material is not nearly enough to make reasonable assumptions about the mechanism of halon action. According to the latest data, the rate 

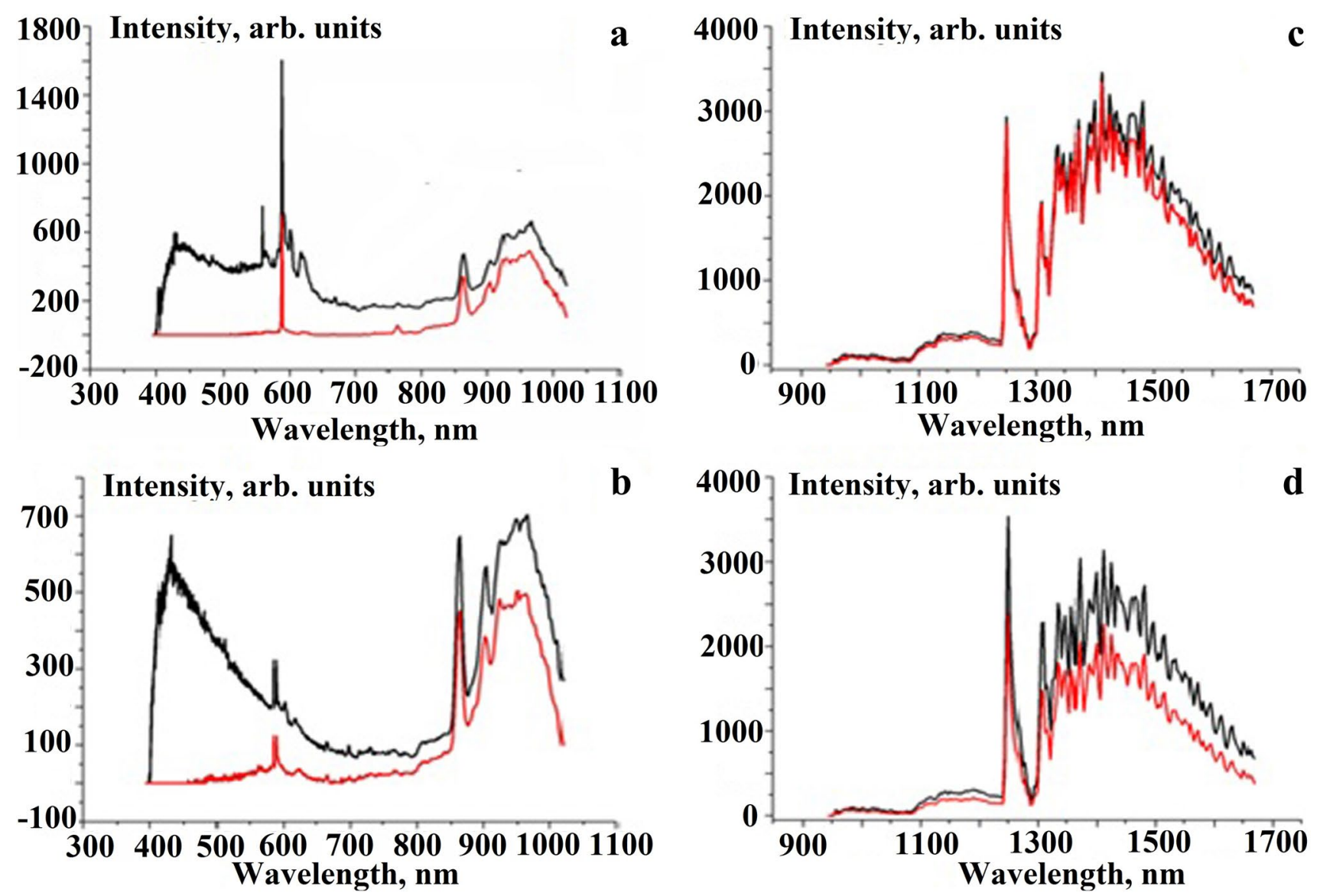

Fig. 6 Emission spectra of ignition. a $\left(\mathrm{H}_{2}+\mathrm{O}_{2}\right)_{\text {stoich }}+10 \% \mathrm{CF}_{2} \mathrm{Cl}_{2}$ and $\left(\mathrm{CH}_{4}+\mathrm{O}_{2}\right)$ stoich $+10 \% \mathrm{CF}_{2} \mathrm{Cl}_{2}$, obtained for a spectral interval 400-970 nm. b $\left(\mathrm{H}_{2}+\mathrm{O}_{2}\right)_{\text {stoich }}+15 \% \mathrm{CF}_{2} \mathrm{Cl}_{2}$ and $\left(\mathrm{CH}_{4}+\mathrm{O}_{2}\right)$ stoich $+15 \% \mathrm{CF}_{2} \mathrm{Cl}_{2}$, obtained for a spectral interval 400-970 $\mathrm{nm}$, c $\left(\mathrm{H}_{2}+\mathrm{O}_{2}\right)_{\text {stoich }}+10 \% \quad \mathrm{CF}_{2} \mathrm{Cl}_{2}$ and $\left(\mathrm{CH}_{4}+\mathrm{O}_{2}\right)$ stoich $+10 \% \quad \mathrm{CF}_{2} \mathrm{Cl}_{2}$,

obtained for a spectral interval 970-1700 nm, d $\left(\mathrm{H}_{2}+\mathrm{O}_{2}\right)_{\text {stoich }}+15 \%$ $\mathrm{CF}_{2} \mathrm{Cl}_{2}$ and $\left(\mathrm{CH}_{4}+\mathrm{O}_{2}\right)$ stoich $+15 \% \mathrm{CF}_{2} \mathrm{Cl}_{2}$, obtained for a spectral interval $970-1700 \mathrm{~nm}$. Initial pressure is 100 Torr. The spectrum with the maximum intensity is chosen from the time sequence of spectra for each experiment

constant of the reaction of atoms of oxygen with halon [28]

$\mathrm{O}^{1} \mathrm{D}+\mathrm{CF}_{2} \mathrm{Cl}_{2} \rightarrow 2 \mathrm{Cl}+$ products $\quad k=1 \cdot 2 \cdot 10^{-10} \mathrm{~cm}^{3} \mathrm{~mole}^{-1} \mathrm{~s}^{-1}$

i.e. (2) is a rather fast reaction, however, in this reaction $\mathrm{HF}$ is not formed.

In [29] an estimate of the reaction rate constant is given (in [30], however, it is claimed that this reaction practically does not occur)

inhibition of methane oxidation with halon. Notice that in the above reactions, the formation of experimentally detected $\mathrm{CF}_{2} \mathrm{O}$ is not discussed at all.

Let's consider the possible reactions of $\mathrm{CH}_{3}$ radical. In the reaction of a chlorine atom separation from $\mathrm{CCl}_{4}, \mathrm{CFCl}_{3}$ and $\mathrm{CF}_{2} \mathrm{Cl}_{2}$ with $\mathrm{CH}_{3}$ radicals at $128{ }^{\circ} \mathrm{C}$ [31], the reaction rate values obtained for these three reactions are in the relation 1:24:126. The data of [32] allow estimating a rate constant of the reaction (if the results $[31,32]$ are true ones)

$\mathrm{OH}+\mathrm{CF}_{2} \mathrm{Cl}_{2} \rightarrow$ products $\left(\mathrm{CClF}_{2}+\mathrm{HOCl}\right) k=1.0 \times 10^{-12} \mathrm{~cm}^{3} \mathrm{~mole}^{-1} \mathrm{~s}^{-1}$

In this fast reaction, formation of $\mathrm{HF}$ is not also considered. However, if the molecules HF are formed in this $\mathrm{CH}_{3}+\mathrm{CF}_{2} \mathrm{Cl}_{2} \rightarrow$ products $\mathrm{k}(4)$ reaction (for example, in almost thermoneutral reaction $\mathrm{OH}+\mathrm{CF}_{2} \mathrm{Cl}_{2} \rightarrow \mathrm{COFCl}+\mathrm{HF}+\mathrm{Cl}$ [27]), it could not explain weak inhibition of hydrogen oxidation and strong 
In [32] the rate constants of the following reactions are measured
Vibrationally excited molecules HF $(v=3)$ and $\mathrm{HF}(v=2)$ are for the first time detected in the products of combustion

$\mathrm{CH}_{3}+\mathrm{CCl}_{4} \rightarrow \mathrm{CH}_{3} \mathrm{Cl}+\mathrm{CCl}_{3} \quad \mathrm{k}(5)=10^{9} \exp (-10000 / \mathrm{RT}) \mathrm{cm}^{3} \mathrm{~mole}^{-1} \mathrm{~s}^{-1}$

$\mathrm{CH}_{3}+\mathrm{CCl}_{3} \mathrm{Br} \rightarrow \mathrm{CH}_{3} \mathrm{Br}+\mathrm{CCl}_{3} \quad \mathrm{k}(6)=10^{8} \exp (-3500 / \mathrm{RT}) \mathrm{cm}^{3} \mathrm{~mole}^{-1} \mathrm{~s}^{-1}$

The estimate of the rate of reaction (4) makes $k(4) \approx 126 \times k(5)$, in the assumption that the activation energy of a rate constant of the reaction (4) makes some average of activation energies of reactions (5) and (6), i.e. $\mathrm{k}(4) \approx 10^{9} \exp (-5000 / \mathrm{RT}) \mathrm{cm}^{3} \mathrm{~mol}^{-1} \mathrm{~s}^{-1}$. The obtained value of $k(4)$ corresponds to a rather slow reaction, which cannot be responsible for effective inhibition of gas-phase methane oxidation.

It should be noted also that completely fluorinated hydrocarbons are worse inhibitors, than $\mathrm{CF}_{2} \mathrm{Cl}_{2}$. For example, as is stated above, the most effective "ozone-safe" inhibitor is $\mathrm{C}_{4} \mathrm{~F}_{10}$, its minimum effective concentration makes $6 \%$ [11]. In addition, we showed earlier that $0.9 \%$ perluorodecaline $\mathrm{C}_{10} \mathrm{~F}_{18}$ does not completely inhibit oxidation of stoichiometric methane-air mix; it is required to dilute this mix with carbon dioxide (15\%) for complete inhibition [33].

It means that, as well as in case of hydrogen oxidation, inhibition of methane oxidation with $\mathrm{CF}_{2} \mathrm{Cl}_{2}$ is caused by some cycle of reactions, which nature as well as the values of their rate constants, requires a substantial clarification.

\section{Conclusions}

It is established that the concentration limit of ignition of a premixed $\mathrm{H}_{2}$-air mix in the presence of $\mathrm{CF}_{2} \mathrm{Cl}_{2}$ at $1 \mathrm{~atm}$ exceeds $10 \%$, whereas the inhibitor limit of ignition of the premixed methane-air mix makes $1 \% \mathrm{CF}_{2} \mathrm{Cl}_{2}$. It means that $\mathrm{CF}_{2} \mathrm{Cl}_{2}$ is an effective inhibitor to prevent undesirable ignition of methane-air mixes at atmospheric pressure. It is experimentally shown that the concentration limits of the initiated combustion known from literature are meaningful only for previously prepared mixes. If the mixes are prepared just before the experiment, then the existence or the lack of ignition is determined by both an order of injection of mixture components, and the geometry of an installation. Therefore, the inhibition with halons can hardly be used to address the challenges of safety in mines. Thus, the influence of gasdynamic factors on the efficiency of inhibition is revealed.

It is shown that the active centers of hydrogen and methane combustion determining the development of combustion process have a different chemical nature. of hydrogen and methane in the presence of $\mathrm{CF}_{2} \mathrm{Cl}_{2}$. It can be promising phenomenon in laser chemical applications.

It is experimentally shown that the intensity of $\mathrm{HF}(v=3)$ and $\mathrm{HF}(\mathrm{V}=2)$ bands in methane combustion in oxygen is higher than in $2 \mathrm{H}_{2}+\mathrm{O}_{2}$ combustion in the presence of the same amount of halon. It means that the reaction with $\mathrm{CF}_{2} \mathrm{Cl}_{2}$ leading to $\mathrm{HF}(\mathrm{v}=2,3)$ formation in methane combustion has to include the active center of methane combustion. Besides, as $\mathrm{CF}_{2} \mathrm{Cl}_{2}$ is an effective inhibitor of methane combustion, this active center has to participate in the elementary act of chain branching or chain propagation as well as to contain a hydrogen atom to form $\mathrm{HF}$ molecule.

\section{Compliance with ethical standards}

Conflict of interest The authors declare that they have no competing interests.

\section{References}

1. Hastie JW (1973) Molecular basis of flame inhibition. J Res Natl Bur Stand A Phy Chem 77:735-764

2. Coward HF, Jones GW (1952) Limits of flammability of gases and vapors. Bulletin 503. Bureau of Mines, Washington

3. Zabetakis MG (1965) Flammability characteristics of combustible gases and vapors. Bulletin 627. Bureau of Mines, Washington

4. Linteris GT, Rumminger MD, Babushok V, Tsang W (2001) Flame inhibition by ferrocene and blends of inert and catalytic agents. In: Proceedings of the 28th international symposium on combustion, London, pp 33-47

5. Kopylova OA, Romanov VV, Prochorova Al, Kopylov IS (2017) Review of thermodynamic characteristics of R-134A, R-410A and $\mathrm{R}-407 \mathrm{C}$ coolants for the air conditioning system. Young Scientist. https://moluch.ru/archive/160/45004. Accessed 19 July 2019

6. Jayaweera TM, Melius CF, Pitz WJ, Westbrook CK, Korobeinichev OP, Shvartsberg VM, Shmakov AG, Rybitskaya IV, Curran HJ (2001) Flame inhibition by phosphorus-containing compounds over a range of equivalence ratios. In: Proceedings of the joint meeting combustion The Insttitute Oakland, California, pp 33-44

7. Emergency and continuous exposure limits for selected airborne contaminants (1984) National Academy Press Committee on Toxicology Board on Toxicology and Environmental Health Hazards Commission on Life Sciences, National Research Council Washington DC 2:34-40 
8. Semenov NN (1958) On some problems of chemical kinetics and reaction ability, 2 nd edn. Academy of Sciences of the USSR, Moscow (in Russian)

9. Karasevich YuK (2009) Kinetics of chemical ionization in shock waves. IV. Kinetic model of ionization at acetylene oxidation. Kinet Catal 50:617-626

10. Azatyan VV, Baklanov DI, Merzhanov AG et al (2001) Inhibition of developed detonation of hydrogen-air mixtures. Dokl Phys Chem 376:1-4

11. Rubtsov NM, Azatyan VV, Borodulin RR (1980) Rate constants of chain origination and propagation in nitrogen trichloride decomposition. Bull Acad Sci USSR Div Chem Sci 29:1165-1170

12. Golov NV (2017) Features of ignition and burning of combustible gases and vapors in various oxidizing environments. Dissertation, Institute of Fire Safety VNIIPO Russian Federation (in Russian)

13. Rubtsov NM, Tsvetkov Gl, Chernysh VI (2008) Different effects of active minor admixtures on hydrogen and methane ignitions. Kinet Catal 49:344-351

14. Rubtsov NM (2016) The modes of gaseous combustion. Springer, Cham

15. Babushok VI, Linteris GT, Meier OC, Pagliaro JL (2014) Flame inhibition by $\mathrm{CF}_{3} \mathrm{CHCl}_{2}$ (HCFC-123) Combust. Sci Technol 186:792-814

16. Troshin KYA, Shamshin IO, Smetanyuk VA, Borisov AA (2017) Self-ignition and combustion of gas mixtures in a medium with vortex flow. Russ J Phys Chem B 11:952-962

17. Borisov AA, Knorre VG, Kudrjashova EL, Troshin KYA (1998) On temperature measurement in an induction period of the ignition of homogeneous gas mixtures in rapid mixture injection static setup. Chem Phys Rep B 17:105-109

18. Rubtsov NM, Vinogradov AN, Kalinin AP, Chernysh VI et al (2016) Cellular combustion and delay periods of ignition of a nearly stoichiometric $\mathrm{H}_{2}$-air mixture over a platinum surface. Mendeleev Commun 26:160-162

19. Azatyan VV, Shebeko YuN, Bolodyan IA, Navtsenya VYu (2006) Effect of diluents of various chemical nature on the flammability limits of gas mixtures. Combust Explos Shock Waves 6:708-714

20. Lewis B, Von Elbe G (1987) Combustion, explosions and flame in gases. Acad Press, New York

21. Rubtsov NM (2017) Key factors of combustion. From kinetics to gas dynamics. Springer, Cham
22. Herzberg G. (1950) Molecular spectra and molecular structure. In: Spectra of diatomic molecules, vol 1, 2nd ed, Van Nostrand, New York

23. Hole OM (2011) In situ HF-concentration measurements in combustion environments using diode laser absorption spectroscopy. A theoretical investigation. Bachelor Project in Physics University of Lund, Lund

24. Grytsinin S, Korchagina EG, Kossyi IA, Misakyan MA, Silakov VP, Tarasova NM, Temchin SM (2001) Decomposition of chlorine and (or) fluorine-bearing substances in a gas mixture ignited by a slipping surface discharge. Plasma Sources Sci Technol 10:125-133

25. McNesby KL, Daniel RG, Widder JM, Miziolek AW (1995) Spectroscopic investigation of atmospheric pressure counterflow diffusion flames inhibited by Halons, U.S. Army Research Laboratory ATTN: AMSRL-WT-PC Report number ARL-TR-857 Aberdeen Proving Ground, MD 21005-5066

26. Rubtsov NM, Seplyarskii BS, Tsvetkov GI, Chernysh VI (2010) Thermal ignition of coal powders in the presence of natural gas, oxygen and chemically active additives. Mendeleev Commun 20:98-100

27. Luo YR (2007) Comprehensive handbook of chemical bond energies. CRC Press, Boca Raton

28. Brasseur GP, Jacob DJ (2017) Modeling of atmospheric chemistry. Cambridge University Press, Cambridge

29. Belikov Y, Nikolayshvili S (2016) The role of the dipole interaction of molecules with charged particles in the polar stratosphere. J Earth Sci Eng 6:115-149

30. Atkinson R, Hansen DA, Pitts JN Jr (1975) Rate constants for the reaction of $\mathrm{OH}$ radicals with $\mathrm{CHF} 2 \mathrm{Cl}, \mathrm{CF} 2 \mathrm{Cl} 2, \mathrm{CFCl} 3$, and $\mathrm{H} 2$ over the temperature range 297-434 K. J Chem Phys 63:1703-1706

31. Hautecloque $\mathrm{S}$ (1977) Réactions des radicaux $\mathrm{CH}_{3}$ avec les molécules $\mathrm{CCl}_{4}, \mathrm{CFCl}_{3}$ et $\mathrm{CF}_{2} \mathrm{Cl}_{2}$. J Photochem 7:83-89

32. Macken KV, Sidebottom HW (1979) The reactions of methyl radicals with chloromethanes. Int J Chem Kinet 11:321-330

33. Rubtsov NM, Tsvetkov GI, Chernysh V., Seplyarsky BS, Azatyan VV (2009) Patent of the Russian Federation RU 2368410 C1: 27 092009 Bul No 27 (in Russian)

Publisher's Note Springer Nature remains neutral with regard to jurisdictional claims in published maps and institutional affiliations. 